\title{
Evaluation of the Efficacy and Threshold of Serum Anti- mullerian Hormone (AMH) Levels for Diagnosis and Prediction of Polycystic Ovary Syndrome (PCOS) Among Indian Women.
}

\section{Sajad Sumji}

Sheri-Kashmir Institute of Medical Sciences

\section{Abid Bhat}

Sheri-Kashmir Institute of Medical Sciences

\section{Aafia Rashid}

Sheri-Kashmir Institute of Medical Sciences

Imtiyaz wani

Sheri-Kashmir Institute of Medical Sciences

Vishnu Vasudevan

Sheri-Kashmir Institute of Medical Sciences

Tajali Sehar

Sheri-Kashmir Institute of Medical Sciences

Mohd Ashraf Ganie ( $\square$ ashraf.endo@gmail.com )

Sheri-Kashmir Institute of Medical Sciences https://orcid.org/0000-0002-7649-6749

\section{Research Article}

Keywords: Anti-Mullerian hormone (AMH), Polycystic ovarian morphology (PCOM), Rotterdam criteria, Hyperandrogenism, Oligo/amenorrhea

Posted Date: January 6th, 2022

DOI: https://doi.org/10.21203/rs.3.rs-1224353/v1

License: (c) (i) This work is licensed under a Creative Commons Attribution 4.0 International License. Read Full License 


\section{Abstract}

Purpose: PCOS women exhibit higher levels of AMH and has been proposed to add value to diagnosis of PCOS incase ambiguity. However, variable cutoffs of AHM for PCOS prediction have been reported. This study was designed to determine diagnostic threshold of serum AMH levels and its correlation with clinical, hormonal and ultrasonographic parameters among women with PCOS.

Materials: In this prospective study, 113 women with PCOS as per Rotterdam criteria 2003 and 75 normo-ovulatory women were included. Clinical, biochemical, hormonal and sonographic assessment in addition to serum AMH levels were determined using standard methodology.

Results: Mean age was comparable ( $23.43 \pm 3.42 \mathrm{vs} .24 .21 \pm 3.18$ years) between cases and controls. The mean number of menstrual cycles per year were lower while as mean BMI, FG score, and serum testosterone were higher in cases than controls $(\mathrm{p}<0.05)$. The mean serum AMH level was significantly higher in PCOS group $(7.84 \pm 3.67 \mathrm{vs}$. $3.23 \pm 1.56 \mathrm{ng} / \mathrm{mL}$ ) than controls. The serum AMH levels showed a positive correlation $(p<0.05)$ with $\mathrm{LH} / \mathrm{FSH}$ ratio $(r=0.206, p=0.029)$, number of ovarian follicles $(r=0.461)$ and volume, $(r=0.521)$, but no correlation significant with age and BMI. As per receiver operating characteristic (ROC) curve, cut-off was worked out to be $3.76 \mathrm{ng} / \mathrm{mL}$ with $86.7 \%$ sensitivity and $62.7 \%$ specificity.

Conclusion: Serum AMH levels correlate positively with PCOM among PCOS women and may be a potent diagnostic marker of ovarian dysfunction either alone or in conjunction with other tools to ensure timely diagnosis and early treatment of the disorder.

\section{Introduction}

Polycystic ovary syndrome (PCOS) is a genetically intricate commonest endocrine disorder among reproductive aged women, [1], and is associated with diverse health issues such as menstrual disturbances, ovulatory dysfunction, infertility[2], and hyperandrogenism [3]. Women suffering from PCOS display an increased risk of metabolic aberrations[4], including insulin resistance (IR) [4], type 2 diabetes mellitus (T2DM) [5], dyslipidemia[6], obesity [7], cardiovascular disease (CVD) [8] and mitotic risks. PCOS also increase the risk for obstructive sleep apnea[9], depression[10] and non-alcoholic fatty liver disease (NAFLD)[11]. The prevalence of PCOS varies in accordance with origin of studies, age groups included, diagnostic criteria employed [12]. National Institutes of Health (NIH; 1990), Rotterdam (2003) and Androgen Excess and Polycystic Ovary Syndrome Society (AE-PCOS) criteria have been used by authors [13].

PCOS is characterized by an increased number of follicles at all growing stages particularly pre-antral and small antral follicles[14], which primarily produce $\mathrm{AMH}$, owing to maturation arrest attributed to abnormal hormonal milieu. As a result, elevated serum AMH is 2-4 fold higher in women suffering from PCOS than in healthy women[15-17] which may partly be attributable to defects in apoptotic processes in maturing follicles [18]. Besides AMH production by granulosa cells in-vitro is also shown to be increased 75 fold higher in anovulatory PCOS and 20 fold more in normo-ovulatory PCOS in comparison to normal ovaries [19] and is positively correlated with serum androgens $[20,21]$.

Serum AMH assay is a superior marker of ovarian reserve [22], being non-invasive and stable from one menstrual cycle to another $[23,24]$. AMH is proposed as a surrogate marker for PCOS diagnosis, although different cutoff values have been reported in various studies[25]. The meta-analysis of AMH in diagnosing symptomatic PCOS 
women demonstrated $79.4 \%$ specificity and $82.8 \%$ sensitivity at cutoff value of $4.7 \mathrm{ng} / \mathrm{mL}[26]$. This variation in cutoff values has been attributed to ethinicity, obesity, vitamin D deficiency, and methods of estimation [27-29]. Therefore,AMH is yet to be adopted as a part of standard diagnostic criteria for PCOS due to this variability and lack of international standard [30].Data in our population is scant and hence the present study was undertaken to analyze serum AMH levels among Indian women with PCOS and to correlate it with clinical, hormonal and ultrasonographic parameters to evaluate the utility of $\mathrm{AMH}$ in the prediction of PCOS.

\section{Materials And Methods}

In this prospective study, women presenting between January 2017 to July 2018 with symptoms suggestive of PCOS such as oligomenorrhea and/or clinical hyperandrogenism and/or ultrasonography indicative of PCOM were informed about the study. Those who expressed desire and signed an informed consent were enrolled in the study. A total of 188 pre-menopausal women belonging to the age group of 18 to 35 years were recruited. The study was conducted as per Helsinki Declaration, and was approved by Institutional Ethics Committee.

\section{Study subjects}

Cases: A total of 113 cases (aged 18-35 years) with PCOS were enrolled in the current study. PCOS was defined when at least two of the three components were present, according to the Rotterdam criteria. Clinical hyperandrogenism (HA) was defined by a modified Ferriman and Gallwey (FG) score of greater than 8 with or without presence of acne and androgenic alopecia. Biochemical HA was defined as an elevation of serum total testosterone levels above 97.5 percentile limits, (i.e. $>0.45 \mathrm{ng} / \mathrm{mL}$ or $2.1 \mathrm{nmol} / \mathrm{L}$ ).

Controls: Age-matched healthy women ( $n=75)$ with regular menstrual cycles (cycle length of 25-35 days) with no evidence of hirsutism, acne, alopecia or endocrine dysfunction and PCOM on trans-abdominal ultrasonography were taken as controls. Subjects were recruited as a part of community outreach programs conducted by the department of Clinical Research periodically.

\section{Clinical assessment and anthropometric evaluation}

A pre-validated questionnaire was administered to all the subjects that included recording of medical facts such as menstrual cyclicity (age of menarche, cycle interval, cycle length), weight trajectory, symptoms of hyperandrogenism (unwanted male pattern hair growth, moderate to severe or treatment resistant acne vulgaris, androgenic alopecia), infertility etc. Oligomenorrhea was defined as inter-menstrual interval of $>35$ days or less than 8 cycles per year while as no menstrual cycle for $>6$ months was labeled as amenorrhea and $>12$ cycles per year was defined as polymenorrhea. Details of medications if any, including those of various health events such as clinically significant cardiovascular, liver, lung, neurologic, renal, musculoskeletal dysfunction etc. were recorded and women with these conditions were excluded. Other exclusions included non-classical adrenal hyperplasia (NCAH), Cushing's syndrome, androgen secreting tumors, hyperprolactinemia and thyroid dysfunction.

Besides these, women with known medication history in last six months that included use of one or more drugs like insulin sensitizers, steroids, anti-androgens, oral contraceptives, anti-depressants, lipid-lowering agents, or other drugs known to effect glucose tolerance, insulin sensitivity etc. were also excluded from the study.

All the enrolled women underwent a brief general physical and systemic examination followed by detailed anthropometry -measurement of height (cms), weight (kgs), waist circumference (cms) with calculation of BMI 
$\left(\mathrm{Kg} / \mathrm{m}^{2}\right)$ using standardized scales (SECA-18, Hamburg, Germany) as a mean of three readings. Waist circumference was measured at the narrowest portion of the torso, approximately midway between the lower costal margin and iliac crest. Blood pressure (systolic and diastolic) $\mathrm{mm}$ of $\mathrm{Hg}$ was calculated from the mean of three readings using standard calibrated instrument (Omron 714, Kyoto Japan). Evaluation of hirsutism was done by using modified Ferriman-Gallwey (mFG) score by a single observer. The densities of terminal hair over 9 specific sites were scored from 0 to 4 and a total score was calculated. Acne vulgaris was graded as per standard guideline ( $0=$ no acne; $1=$ minor acne; $2=$ minor acne on face only and $3=$ severe acne on face, back and or chest) and androgenic alopecia was graded from I-III as per Ludwig scale as was acanthosis nigricans (1-3 as per severity).

\section{Laboratory Evaluation}

All the women slated for testing were asked to report after an overnight (10-12hr) fast at 8:00 hours on a day arranged in such a way that the samples for T4, TSH, LH, FSH, prolactin (PRL), serum total testosterone, cortisol (morning), 17-hydroxyprogesterone (17-OHP) and serum AMH were collected from days 2nd to 7th of spontaneous or medroxyprogesterone-induced menstrual cycle. Oral glucose tolerance test (OGTT) was performed using venous blood samples obtained at baseline ( $0 \mathrm{~min}$ ), 60 minutes and 120 minutes after an oral load of $75 \mathrm{gm}$ anhydrous glucose dissolved in 200-300 ml of water. Aliquots for hemogram, LFT, KFT, calcium, phosphorous, uric acid and lipid profile were collected from the basal sample. ACTH-stimulated 17-OHP or overnight dexamethasonesuppressed cortisol test was done to rule out NCAH or Cushing's syndrome after the baseline, wherever necessary. Trans-abdominal and transvaginal ultrasonography (wherever appropriate) was performed using GE LOGIQP5 PRO USG (Chicago, USA) equipment to demonstrate any evidence of PCOM described in literature[31, 32] i.e. presence of 10 or more peripheral follicles each measuring $2-8 \mathrm{~mm}$ in size with echogenic ovarian stroma and/or increased $(>10 \mathrm{ml})$ ovarian volume in all subjects by a single observer following a common SOP.

\section{Assays}

Sample for PRL, TSH, T3, T4, LH, FSH and total testosterone were assayed using a commercial electrochemiluminescent immunoassay using (COBAS e-411, Roche Diagnostics, Indiana, USA). Serum AMH levels were assayed using the ELISA kits (Ansh Labs 445 Medical Centre Blvd, U.S.A). Plasma glucose and other parameters-uric acid, lipids, calcium, phosphorous, LFT, KFT etc. were estimated on a fully automated biochemistry analyzer (Respons ${ }^{\circledR 910}$, DiaSys, Holzheim, Germany). The inter and intra assay coefficients of variation wee according to manufacturer's protocol.

\section{Statistical Analysis}

SPSS version 26.0 was used to analyze the date and its was expressed as Mean \pm SD. Group differences were compared using the Chi-square test for categorical variables and the't' test for continuous variables. For comparing continuous variables ANOVA with f-test was used. Cut-off values of AMH levels as a predictor of the diagnosis of PCOS were analyzed using a Receiver Operating Characteristic (ROC) procedure. Pearson correlation was used to analyze the association of serum AMH levels with various clinical, hormonal and ultrasonographic parameters. The $p$-value $<0.05$ was considered statistically significant.

\section{Results}

The baseline characteristics of the PCOS cases and the controls are summarized in Table 1 and 2 respectively. The mean age of cases and controls was comparable (23.43 \pm 3.42 years vs. $24.21 \pm 3.18$ years) respectively $(p=0.118)$. 
Mean number of menstrual cycles per year for cases and controls was $7.16 \pm 3.55$ vs. $11.55 \pm 4.22(p=0.001)$ while their $\mathrm{mFG}$ scores were $13.60 \pm 4.43$ vs. $4.21 \pm 2.18$ respectively $(p=0.001)$. Mean BMI of cases and controls was $23.26 \pm 3.76$ vs. $22.23 \pm 3.31 \mathrm{~kg} / \mathrm{m}^{2}$ ( $p=0.048$ ). Among PCOS group, $2.13 \%$ were underweight, $18.09 \%$ overweight and $7.45 \%$ were obese. As shown in Figure 1, Mild hirsutism (FG score 8 to 15) was seen in $52.2 \%$ and severe hirsutism (FG score of $\geq 16$ ) in $17.7 \%$, in PCOS group while as $29 \%$ of cases had grade $1,18 \%$ grade 2 and $3 \%$ had grade 3 acne respectively. About 28\%, $8 \%$ and $3 \%$ of cases had grade 1, 2 and 3 androgenic alopecia respectively. There was no acanthosis in $78 \%$ of the cases.

Table 1

Comparison of clinical and hormonal characteristics of PCOS women and healthy controls

\begin{tabular}{|llll|}
\hline Parameter & PCOS & Healthy Controls & P-value* \\
& $\mathrm{n}=113$ & $\mathrm{n}=75$ & \\
\hline Age (years) & $23.43 \pm 3.428$ & $24.21 \pm 3.18$ & 0.118 \\
\hline Number of menstrual cycles/year & $7.16 \pm 3.55$ & $11.5 \pm 2.22$ & 0.001 \\
\hline Modified Ferriman Gallway score (mFG) & $13.60 \pm 4.43$ & $4.21 \pm 2.18$ & 0.001 \\
\hline BMI (kg/m ${ }^{2}$ ) & $23.26 \pm 3.76$ & $22.23 \pm 2.97$ & 0.048 \\
\hline Waist circumference (cm) & $83.09 \pm 10.78$ & $73.16 \pm 11.06$ & 0.002 \\
\hline SBP (mmHg) & $113.88 \pm 10.40$ & $112.98 \pm 9.04$ & 0.542 \\
\hline DBP (mmHg) & $75.92 \pm 7.77$ & $75.84 \pm 7.57$ & 0.938 \\
\hline TSH (mIU/L) & $3.45 \pm 1.63$ & $3.40 \pm 1.20$ & 0.800 \\
\hline T3 (ng/ml) & $1.04 \pm 0.21$ & $1.03 \pm 0.24$ & 0.763 \\
\hline T4 (mcg/dl) & $8.35 \pm 1.66$ & $8.62 \pm 1.31$ & 0.245 \\
\hline LH (IU/L) & $8.53 \pm 4.23$ & $4.60 \pm 1.55$ & 0.001 \\
\hline FSH (IU/L) & $5.17 \pm 1.99$ & $5.81 \pm 1.97$ & 0.061 \\
\hline LH/FSH Ratio & $1.64 \pm 0.91$ & $0.79 \pm 0.48$ & 0.001 \\
\hline Serum total Testosterone (ng/dl) & $61.36 \pm 23.49$ & $30.76 \pm 12.67$ & 0.001 \\
\hline AMH (ng/ml) & $7.84 \pm 3.67$ & $3.23 \pm 1.56$ & 0.001 \\
\hline *p<0.05 is considered statistically significant & & \\
\hline
\end{tabular}


Table 2

Comparison of biochemical characteristics of PCOS women and healthy controls.

\begin{tabular}{|c|c|c|c|}
\hline Parameter & $\begin{array}{l}\text { PCOS } \\
n=113\end{array}$ & $\begin{array}{l}\text { Healthy Controls } \\
\mathrm{n}=75\end{array}$ & P-value* \\
\hline Plasma glucose- $0 \mathrm{hr}(\mathrm{mg} / \mathrm{dL})$ & $88.41 \pm 11.19$ & $82.73 \pm 10.90$ & 0.001 \\
\hline Post OGTT-1hr (mg/dL) & $99.75 \pm 22.47$ & $96.42 \pm 16.83$ & 0.275 \\
\hline Post OGTT-2hr (mg/dL) & $103.50 \pm 23.01$ & $106.29 \pm 22.17$ & 0.410 \\
\hline Serum total cholesterol (mg/dL) & $181.62 \pm 37.39$ & $181.00 \pm 35.07$ & 0.908 \\
\hline Serum Triglycerides (mg/dL) & $155.25 \pm 63.04$ & $134.42 \pm 56.698$ & 0.022 \\
\hline Serum High density lipoprotein (HDL) cholestrol (mg/dL) & $48.09 \pm 8.16$ & $52.49 \pm 7.07$ & 0.001 \\
\hline Serum Low density lipoprotein (LDL) cholestrol (mg/dL) & $102.61 \pm 27.53$ & $101.73 \pm 26.03$ & 0.827 \\
\hline Serum total Bilirubin $(\mathrm{mg} / \mathrm{dL})$ & $0.92 \pm 0.39$ & $0.90 \pm 0.47$ & 0.723 \\
\hline Serum Aspartate transaminase (AST) (U/L) & $30.07 \pm 14.38$ & $28.41 \pm 12.82$ & 0.421 \\
\hline Serum Alanine transaminase (ALT) $(\mathrm{U} / \mathrm{L})$ & $29.28 \pm 17.84$ & $24.61 \pm 12.72$ & 0.052 \\
\hline Serum Alkaline Phosphatase (ALP) (U/L) & $109.89 \pm 22.42$ & $96.62 \pm 23.93$ & 0.001 \\
\hline Serum Total protein $(\mathrm{g} / \mathrm{dL})$ & $7.27 \pm 0.56$ & $7.12 \pm 0.47$ & 0.061 \\
\hline Serum Albumin (g/dL) & $4.23 \pm 0.66$ & $4.12 \pm 0.46$ & 0.221 \\
\hline Serum Urea $(\mathrm{mg} / \mathrm{dL})$ & $17.81 \pm 5.85$ & $20.92 \pm 7.18$ & 0.001 \\
\hline Serum Creatinine (mg/dL) & $0.72 \pm 0.22$ & $0.86 \pm 0.14$ & 0.01 \\
\hline Serum Uric acid (mg/dL) & $3.91 \pm 1.10$ & $3.80 \pm 1.11$ & 0.511 \\
\hline
\end{tabular}

Among the biochemical parameters plasma glucose, serum HDL and serum SGPT were significantly different among the groups as expected (Table 2). Mean LH value of cases and controls was found to be $8.53 \pm 4.23$ vs $4.60 \pm 1.55 \mathrm{lU} / \mathrm{ml}$ significantly high $(\mathrm{p}=0.001)$ as were mean serum total testosterone levels $(61.36 \pm 23.49 \mathrm{vs}$. $30.76 \pm 12.67 \mathrm{ng} / \mathrm{ml}$ ). The mean AMH level in cases was $7.84 \pm 3.67 \mathrm{ng} / \mathrm{ml}$ whereas it was $3.23 \pm 1.56 \mathrm{ng} / \mathrm{ml} \mathrm{in}$ the control group $(p=0.01)$ (Table 3$)$. The women with PCOS were grouped in four phenotypes as shown in Table 4. The most common PCOS phenotype in our study was phenotype A followed by D with AMH levels of $12.67 \pm 3.46$ $\mathrm{ng} / \mathrm{ml}$ and $11.87 \pm 3.40 \mathrm{ng} / \mathrm{ml}$ respectively. The least common phenotype was B with serum AMH levels of $7.28 \pm$ $1.60 \mathrm{ng} / \mathrm{ml}$. 
Table 3

Pearson's correlation of serum AMH levels with clinical, hormonal and ultrasonographic parameters among PCOS women.

\begin{tabular}{|lll|}
\hline Variable & Correlation coefficient(r) & $P$-value \\
\hline Age (in years) & -0.076 & 0.421 \\
\hline FG score & 0.014 & 0.885 \\
\hline BMI (kg/m²) & -0.082 & 0.385 \\
\hline Waist (cm) & 0.059 & 0.535 \\
\hline LH (IU/L) & 0.148 & 0.119 \\
\hline FSH (IU/L) & -0.148 & 0.117 \\
\hline LH/FSH Ratio & 0.206 & $0.029 *$ \\
\hline Testosterone (ng/dl) & 0.097 & 0.307 \\
\hline No. of follicles & 0.461 & $0.001 *$ \\
\hline Ovarian Volume & 0.521 & $0.001 *$ \\
\hline *p<0.05 is considered statistically significant. & \\
\hline
\end{tabular}

Table 4

AMH levels among PCOS women based on phenotype

\begin{tabular}{|llllllll|}
\hline Phenotype & OA & HA & PCO & Frequency & $\%$ & AMH $(\mathrm{ng} / \mathrm{ml})$ \\
\hline $\mathrm{A}$ & + & + & + & 41 & 36.28 & $12.67 \pm 3.46$ \\
$\mathrm{~B}$ & + & + & - & 17 & 15.04 & $7.28 \pm 1.60$ \\
$\mathrm{C}$ & - & + & + & 21 & & 18.59 & $8.91 \pm 3.21$ \\
\hline $\mathrm{D}$ & + & - & + & 34 & & 30.09 & $11.87 \pm 3.40$ \\
Abbreviations & & & & & & & \\
HA: Hyperandrogenism & & & & & & \\
OA: Oligoanovolution \\
PCO: Poly cystic ovary
\end{tabular}

For determining the AMH diagnostic cut-off, the ROC curve was used. A $3.76 \mathrm{ng} / \mathrm{mL}$ AMH cut-off level was determined with a sensitivity of $86.7 \%$ and a specificity of $62.7 \%$ with area under the curve equaling $0.875(0.826$ 0.924). Among cases, AMH levels positively correlated with $\mathrm{LH} / \mathrm{FSH}$ ratio $(r=0.206, p=0.029)$, polycystic ovarian morphology (number of follicles $r=0.461, p=0.001$; ovarian volume $r=0.521, p=0.001$ ) whereas there was trend towards negative correlation of AMH with age $(r=-0.076, p=0.421)$ and $B M I(r=-0.082, p=0.385)$. A positive non- 
significant correlation was found with FG score $(r=0.014 ; p=0.885)$ and serum total testosterone $(r=0.097 ; p=0.307)$ respectively. The scatter plots are depicted in Figure 2.

\section{Discussion}

There is no solitary criterion for the diagnosis of PCOS and the variability in the prevalence rates under different diagnostic criteria highlights an immense need for other modalities to help in positive diagnosis of PCOS[33] and reduce uncertainity. Even with the most technically advanced ultrasonography devices, it can be difficult to count antral follicles trans-abdominally in virgins or the obese. AMH has been shown to be an alternative marker for the follicle number and an index of ovulatory dysfunction due to its higher sensitivity and specificity[34, 35]. Our findings showed that compared to healthy controls, women with PCOS had significantly higher levels of serum $\mathrm{AMH}$ which was accompanied by higher levels of serum total testosterone levels. These results are in concordance with the previous reported studies[36]. Since AMH is produced by granulosa cells of both preantral and small antral follicles, increase substantially among PCOS women, so AMH increase in PCOS[37]. The ability of serum $\mathrm{AMH}$ level to serve as a marker for the diagnosis of PCOS has been reported in many studies with inconsistent threshold values[35,38]. In this study, we report a threshold of $3.76 \mathrm{ng} / \mathrm{mL}$ with $86.7 \%$ sensitivity and $62.7 \%$ specificity in our study population. While as, earlier studies have reported a threshold ranging from 2.52 to 10 $\mathrm{ng} / \mathrm{mL}[25,34,39,40]$ as depicted in Table 5, Our results are consistent with the results by Sahmay et al.[41] who showed $80.7 \%$ sensitivity and $74.7 \%$ specificity for AMH cutoff value of $3.8 \mathrm{ng} / \mathrm{mL}$. Our threshold value is slightly lower than that of reported by Iranian[42], Korean[39, 43], French [34] and Chinese observations[44]. Our suggestion for a cut-off value of serum AMH for the diagnosis of PCOS is more reliable, given that the sample size was larger than the previous studies. The inconsistency in serum AMH levels and lack of standard cut-off values may be explained due to differences in the sample size, inclusion criteria, different AMH assay and specified PCOS phenotypes among the studies[45]. Wongwananuruk et al suggested difference in BMI across the populations may contribute to the discrepancy between $\mathrm{AMH}$ cut offs observed across various studies [26], however another study reported BMI had no significant impact on $\mathrm{AMH}$ levels[45]. In this study, we found no significant correlation of $\mathrm{AMH}$ levels with BMI or waist circumference however serum LH was found to be high in lean PCOS patients as compared to obese PCOS patients and this was consistent with findings of the study conducted by Liou et al.[46]. We observed obese women with PCOS had significantly lower LH to FSH ratios than non-obese women with PCOS. A significant $\mathrm{LH} / \mathrm{FSH}$ ratio difference between PCOS women and healthy controls was noted. We report AMH levels to be positively correlated with LH/FSH ratio. 
Table 5

Threshold values of $\mathrm{AMH}$ reported in Literature

\begin{tabular}{|c|c|c|c|c|c|c|c|}
\hline $\begin{array}{l}\text { Author, } \\
\text { Year } \\
\text { Reference }\end{array}$ & Population & $\begin{array}{l}\text { PCOS } \\
\text { Diagnosis } \\
\text { Criteria }\end{array}$ & $\begin{array}{l}\text { Study } \\
\text { Design }\end{array}$ & $\begin{array}{l}\text { No. of } \\
\text { cases/controls }\end{array}$ & $\begin{array}{l}\text { Cut-off } \\
(\mathrm{ng} / \mathrm{ml})\end{array}$ & $\begin{array}{l}\text { Sensitivity } \\
\%\end{array}$ & $\begin{array}{l}\text { Specificity } \\
\%\end{array}$ \\
\hline $\begin{array}{l}\text { Ahmed et } \\
\text { al, } 2019\end{array}$ & Saudi & $\mathrm{R}$ & case-control & $79 / 69$ & 3.19 & 72 & 70 \\
\hline \multicolumn{8}{|l|}{ [29] } \\
\hline $\begin{array}{l}\text { Saxena et } \\
\text { al, } 2017\end{array}$ & India & $\mathrm{R}$ & case-control & $45 / 45$ & 3.44 & 77.8 & 68.9 \\
\hline \multicolumn{8}{|l|}{ [51] } \\
\hline $\begin{array}{l}\text { Song DK } \\
\text { et al, } \\
2016 \text { [39] }\end{array}$ & Korea & $\mathrm{R}$ & $\begin{array}{l}\text { cross- } \\
\text { sectional }\end{array}$ & $270 / 220$ & 10 & 71 & 93 \\
\hline $\begin{array}{l}\text { Wiweko } \\
\text { et al, } \\
2014\end{array}$ & Indonesia & $\mathrm{R}$ & case-control & 71/71 & 4.45 & 76.1 & 74.6 \\
\hline \multicolumn{8}{|l|}{ [36] } \\
\hline $\begin{array}{l}\text { Homburg } \\
\text { et al, } \\
2013 \text { [52] }\end{array}$ & UK & $\mathrm{R}$ & case-control & $90 / 90$ & 6.7 & 60 & 98.2 \\
\hline $\begin{array}{l}\text { Chao et } \\
\text { al, } 2012\end{array}$ & Taiwan & $\mathrm{R}$ & case-control & $45 / 59$ & 3.5 & 74 & 79 \\
\hline \multicolumn{8}{|l|}{ [53] } \\
\hline $\begin{array}{l}\text { Woo et al, } \\
2012\end{array}$ & Korea & $\mathrm{R}$ & $\begin{array}{l}\text { cross- } \\
\text { sectional }\end{array}$ & $87 / 53$ & 7.8 & 75.9 & 86.8 \\
\hline \multicolumn{8}{|l|}{ [54] } \\
\hline $\begin{array}{l}\text { Eilertsen } \\
\text { et al, } \\
2012\end{array}$ & Norway & $\mathrm{R}, \mathrm{AES}$ & case-control & $56^{\mathrm{R}}, 44^{\mathrm{AES}} / 162$ & 2.8 & 94.6 & 97.1 \\
\hline \multicolumn{8}{|l|}{ [55] } \\
\hline $\begin{array}{l}\text { Lin et al, } \\
2011\end{array}$ & Taiwan & $\mathrm{R}$ & prospective & $126 / 164$ & 7.3 & 76 & 70 \\
\hline \multicolumn{8}{|l|}{ [56] } \\
\hline $\begin{array}{l}\text { Dewailly } \\
\text { et al, } \\
2011\end{array}$ & France & $\mathrm{R}$ & prospective & $240 / 105$ & 5.0 & 92 & 97 \\
\hline \multicolumn{8}{|l|}{ [25] } \\
\hline $\begin{array}{l}\text { Li HWR et } \\
\text { al, } 2011\end{array}$ & China & $\mathrm{R}$ & retrospective & $124 / 26$ & 5.9 & 79 & 96 \\
\hline [57] & & & & & & & \\
\hline
\end{tabular}




\begin{tabular}{|llllllll|}
$\begin{array}{l}\text { Li et al, } \\
\text { 2010 }\end{array}$ & China & R & cohort & $47 / 40$ & 8 & 61.7 & 70 \\
[58] & & & & & & \\
$\begin{array}{l}\text { Hart et al, } \\
2010\end{array}$ & Australia & R,NIH & $\begin{array}{l}\text { prospective } \\
\text { cohort }\end{array}$ & $64^{\mathrm{R}}, 36^{\mathrm{NIH}} / 113$ & 4.2 & 53.1 & 69.8 \\
{$[59]$} & & & & & & \\
$\begin{array}{l}\text { Pigny et } \\
\text { al, 2006 }\end{array}$ & France & $\mathrm{R}$ & $\begin{array}{l}\text { prospective } \\
\text { cohort }\end{array}$ & $73 / 96$ & 8.4 & 67 & 92 \\
{$[34]$} & & & & & & & \\
\hline
\end{tabular}

Serum AMH has been proposed to replace variable ultrasound assessment of ovarian follicle in diagnosis of PCO morphology as disrupted folliculogeneis leading to excess antral follicle accumulation underpins the higher serum AMH levels among PCOS women[47]. In the present study, we compared the AMH levels among PCOS women with different PCOS phenotypes. Serum AMH level was highest in Group A (OA+HA+PCO) who had PCO morphology on ultrasound and lowest in group B where no PCOM morphology was found. The results depict association of PCOM with AMH levels. Various studies have reported hyperandrogenism, the hallmark feature of PCOS [48], to increase AMH expression from granulosa cells and ovulatory dysfunction is also associated with AMH levels [49]. The current observations substantiate none of the findings which is in contrast to the study among Turkish women with PCOS [50].

The accuracy and sensitivity of AMH for PCOS was well established in our study and its higher values in serum reflected $\mathrm{AMH}$ as a potential marker of recruited non-growing follicles rather than a simple marker of ovarian reserve. Though sensitivity and specificity of AMH is low in absence of other diagnostic factors to make positive diagnosis of PCOS. Still it is a promising diagnostic tool for PCOS as an adjunct to existing Rotterdam criteria when it is used to replace PCOM.

\section{Conclusion}

The serum AMH level among patients with PCOS correlate positively with LH/FSH ratio and polycystic ovarian morphology (follicle number and ovarian volume). The combination of the serum AMH level with hyperandrogenism and/or oligo-amenorrhea markedly increases the diagnostic accuracy of PCOS and can be introduced as an objective and well-structured criterion for diagnosis of PCOS.

\section{Limitations}

All efforts were made to minimize limitations of the study as far as possible. However, enrolling of healthy volunteers as controls proved to be a minor challenge with the result only 75 volunteers participated in the study. The effect of this limitation on the study was minimized by applying appropriate statistical tests of significance. Besides, HOMA-IR, SHBG and DHEAS levels were not estimated in our study.

\section{Declarations}

\section{Funding:}


This work was supported by parent institutional internal research grant.

\section{Competing Interests:}

The authors have no relevant financial or non-financial interests to disclose.

\section{Author contribution:}

MAG: Project development;

SS: Data collection;

AR, TS, IAW: Data analysis;

$A B, V V$ : Manuscript writing.

All authors have read and approved the final manuscript.

\section{Conflict of interest:}

The authors declare that they have no conflict of interest.

\section{References}

1. Wan, P., et al., Replication study and meta-analysis of selected genetic variants and polycystic ovary syndrome susceptibility in Asian population. Journal of Assisted Reproduction and Genetics, 2021: p. 1-9.

2. Naghshband, Z., et al., Visceral adiposity index and lipid accumulation product as diagnostic markers of metabolic syndrome in South Indians with polycystic ovary syndrome. Journal of Human Reproductive Sciences, 2021. 14(3): p. 234.

3. Ganie, M.A., et al., Association of subclinical hypothyroidism and phenotype, insulin resistance, and lipid parameters in young women with polycystic ovary syndrome. Fertility and sterility, 2011. 95(6): p. 2039-2043.

4. Hsieh, Y.-C., P.-K. Yang, and M.-J. Chen, Metabolic Syndrome in Polycystic Ovary Syndrome. Fertility \& Reproduction, 2021: p. 1-11.

5. Chantrapanichkul, P., et al., Prevalence of type 2 diabetes mellitus compared between lean and overweight/obese patients with polycystic ovarian syndrome: a 5-year follow-up study. Archives of gynecology and obstetrics, 2020. 301(3): p. 809-816.

6. Ishrat, S. and M. Hussain, Prevalence of Insulin Resistance, Dyslipidemia and Metabolic Syndrome in Infertile Women with Polycystic Ovary Syndrome. Journal of Bangladesh College of Physicians and Surgeons, 2021. 39(4): p. 225-232.

7. Šimková, M., et al., Endocrine disruptors, obesity, and cytokines-how relevant are they to PCOS? Physiological research, 2020.69.

8. Wekker, V., et al., Long-term cardiometabolic disease risk in women with PCOS: a systematic review and metaanalysis. Human reproduction update, 2020. 26(6): p. 942-960.

9. Kumarendran, B., et al., Increased risk of obstructive sleep apnoea in women with polycystic ovary syndrome: a population-based cohort study. European journal of endocrinology, 2019. 180(4): p. 265-272. 
10. Dokras, A., et al., Increased risk for abnormal depression scores in women with polycystic ovary syndrome: a systematic review and meta-analysis. Obstetrics \& Gynecology, 2011. 117(1): p. 145-152.

11. Wu, J., et al., A potential link between polycystic ovary syndrome and non-alcoholic fatty liver disease: an update meta-analysis. Reproductive Health, 2018. 15(1): p. 1-9.

12. Mohammad, M.B. and A.M. Seghinsara, Polycystic ovary syndrome (PCOS), diagnostic criteria, and AMH. Asian Pacific journal of cancer prevention: APJCP, 2017. 18(1): p. 17.

13. Dumesic, D.A., et al., Scientific statement on the diagnostic criteria, epidemiology, pathophysiology, and molecular genetics of polycystic ovary syndrome. Endocrine reviews, 2015. 36(5): p. 487-525.

14. Franks, S., J. Stark, and K. Hardy, Follicle dynamics and anovulation in polycystic ovary syndrome. Human reproduction update, 2008. 14(4): p. 367-378.

15. Tal, R., et al., High serum Antimullerian hormone levels are associated with lower live birth rates in women with polycystic ovarian syndrome undergoing assisted reproductive technology. Reproductive Biology and Endocrinology, 2020. 18(1): p. 1-8.

16. Bhide, P., et al., Each small antral follicle in ovaries of women with polycystic ovary syndrome produces more antimüllerian hormone than its counterpart in a normal ovary: an observational cross-sectional study. Fertility and sterility, 2015. 103(2): p. 537-541.

17. Villarroel, C., et al., Polycystic ovarian morphology in adolescents with regular menstrual cycles is associated with elevated anti-Müllerian hormone. Human reproduction, 2011. 26(10): p. 2861-2868.

18. Jarrett, B.Y., et al., Ultrasound characterization of disordered antral follicle development in women with polycystic ovary syndrome. The Journal of Clinical Endocrinology \& Metabolism, 2020. 105(11): p. e3847e3861.

19. Tran, N.D., M.I. Cedars, and M.P. Rosen, The role of anti-müllerian hormone (AMH) in assessing ovarian reserve. The Journal of Clinical Endocrinology \& Metabolism, 2011. 96(12): p. 3609-3614.

20. Dilaver, N., et al., The regulation and signalling of anti-Müllerian hormone in human granulosa cells: relevance to polycystic ovary syndrome. Human Reproduction, 2019. 34(12): p. 2467-2479.

21. Tata, B., et al., Elevated prenatal anti-Müllerian hormone reprograms the fetus and induces polycystic ovary syndrome in adulthood. Nature medicine, 2018. 24(6): p. 834-846.

22. Dumont, A., et al., Role of Anti-Müllerian Hormone in pathophysiology, diagnosis and treatment of Polycystic Ovary Syndrome: a review. Reproductive Biology and Endocrinology, 2015. 13(1): p. 1-10.

23. Tsepelidis, S., et al., Stable serum levels of anti-Müllerian hormone during the menstrual cycle: a prospective study in normo-ovulatory women. Human reproduction, 2007. 22(7): p. 1837-1840.

24. Iwase, A., et al., Anti-Müllerian hormone as a marker of ovarian reserve: What have we learned, and what should we know? Reproductive medicine and biology, 2016. 15(3): p. 127-136.

25. Dewailly, D., et al., Diagnosis of polycystic ovary syndrome (PCOS): revisiting the threshold values of follicle count on ultrasound and of the serum AMH level for the definition of polycystic ovaries. Human reproduction, 2011. 26(11): p. 3123-3129.

26. Wongwananuruk, T., et al., Accuracy of anti-Müllerian hormone and total follicles count to diagnose polycystic ovary syndrome in reproductive women. Taiwanese Journal of Obstetrics and Gynecology, 2018. 57(4): p. 499506.

27. Iliodromiti, S., et al., Can anti-Müllerian hormone predict the diagnosis of polycystic ovary syndrome? A systematic review and meta-analysis of extracted data. The Journal of Clinical Endocrinology \& Metabolism, 
2013. 98(8): p. 3332-3340.

28. Tal, R. and D.B. Seifer, Potential mechanisms for racial and ethnic differences in antimüllerian hormone and ovarian reserve. International journal of endocrinology, 2013. 2013.

29. Ahmed, N., et al., Serum anti-Müllerian hormone in the diagnosis of polycystic ovary syndrome in association with clinical symptoms. Diagnostics, 2019. 9(4): p. 136.

30. Abbara, A., et al., Anti-Müllerian hormone (AMH) in the diagnosis of menstrual disturbance due to polycystic ovarian syndrome. Frontiers in endocrinology, 2019. 10: p. 656.

31. Bello, F. and A. Odeku, Polycystic Ovaries: A common feature in transvaginal scans of gynaecological patients. Annals of Ibadan postgraduate medicine, 2015. 13(2): p. 108-109.

32. Balen, A.H., et al., Ultrasound assessment of the polycystic ovary: international consensus definitions. Human reproduction update, 2003. 9(6): p. 505-514.

33. Aversa, A., et al., Fundamental concepts and novel aspects of polycystic ovarian syndrome: Expert consensus resolutions. Frontiers in endocrinology, 2020. 11.

34. Pigny, P., et al., Serum anti-Mullerian hormone as a surrogate for antral follicle count for definition of the polycystic ovary syndrome. The Journal of Clinical Endocrinology \& Metabolism, 2006. 91(3): p. 941-945.

35. Zhao, Y., et al., Diagnostic value of anti-Müllerian hormone as a biomarker for polycystic ovary syndrome: $A$ meta-analysis update. Endocrine Practice, 2019. 25(10): p. 1056-1066.

36. Wiweko, B., et al., Anti-mullerian hormone as a diagnostic and prognostic tool for PCOS patients. Journal of assisted reproduction and genetics, 2014. 31(10): p. 1311-1316.

37. Dewailly, D., et al., Role of anti-müllerian hormone in the pathogenesis of polycystic ovary syndrome. Frontiers in Endocrinology, 2020. 11.

38. Lauritsen, M., et al., The prevalence of polycystic ovary syndrome in a normal population according to the Rotterdam criteria versus revised criteria including anti-Müllerian hormone. Human reproduction, 2014. 29(4): p. 791-801.

39. Song, D.K., et al., Differentiation between polycystic ovary syndrome and polycystic ovarian morphology by means of an anti-Müllerian hormone cutoff value. The Korean journal of internal medicine, 2016. 32(4): p. 690-698.

40. Tremellen, K. and D. Zander-Fox, Serum anti-Mullerian hormone assessment of ovarian reserve and polycystic ovary syndrome status over the reproductive lifespan. Australian and New Zealand Journal of Obstetrics and Gynaecology, 2015. 55(4): p. 384-389.

41. Sahmay, S., et al., Diagnosis of polycystic ovary syndrome: AMH in combination with clinical symptoms. Journal of assisted reproduction and genetics, 2014. 31(2): p. 213-220.

42. Tehrani, F.R., et al., Age-specific cut-off levels of anti-Müllerian hormone can be used as diagnostic markers for polycystic ovary syndrome. Reproductive Biology and Endocrinology, 2021. 19(1): p. 1-10.

43. Do Kyeong Song, J.-Y.O., H. Lee, and Y.-A. Sung, Differentiation between polycystic ovary syndrome and polycystic ovarian morphology by means of an anti-Müllerian hormone cutoff value. The Korean Journal of Internal Medicine, 2017. 32(4): p. 690.

44. Yue, C.-Y., et al., Threshold value of anti-Mullerian hormone for the diagnosis of polycystic ovary syndrome in Chinese women. PLoS One, 2018. 13(8): p. e0203129. 
45. de Loos, A.D., et al., Antimüllerian hormone to determine polycystic ovarian morphology. Fertility and Sterility, 2021. 116(4): p. 1149-1157.

46. Liou, T.-H., et al., Clinical and biochemical presentations of polycystic ovary syndrome among obese and nonobese women. Fertility and sterility, 2009. 92(6): p. 1960-1965.

47. Fong, S.L., et al., The role of anti-Müllerian hormone in the classification of anovulatory infertility. European Journal of Obstetrics \& Gynecology and Reproductive Biology, 2015. 186: p. 75-79.

48. Ashraf, S., et al., Hyperandrogenism in polycystic ovarian syndrome and role of CYP gene variants: a review. Egyptian Journal of Medical Human Genetics, 2019. 20(1): p. 1-10.

49. Alebić, M., et al., The phenotypic diversity in per-follicle anti-Müllerian hormone production in polycystic ovary syndrome. Human Reproduction, 2015. 30(8): p. 1927-1933.

50. Aydoğmuş, H., et al., Can we use serum Anti-Mullerian hormone to differentiate the diagnosis between polycystic ovary syndrome patients and healthy women with polycystic ovarian morphology and regular menstrual cycles. Saudi medical journal, 2018. 39(10): p. 1011.

\section{Figures}

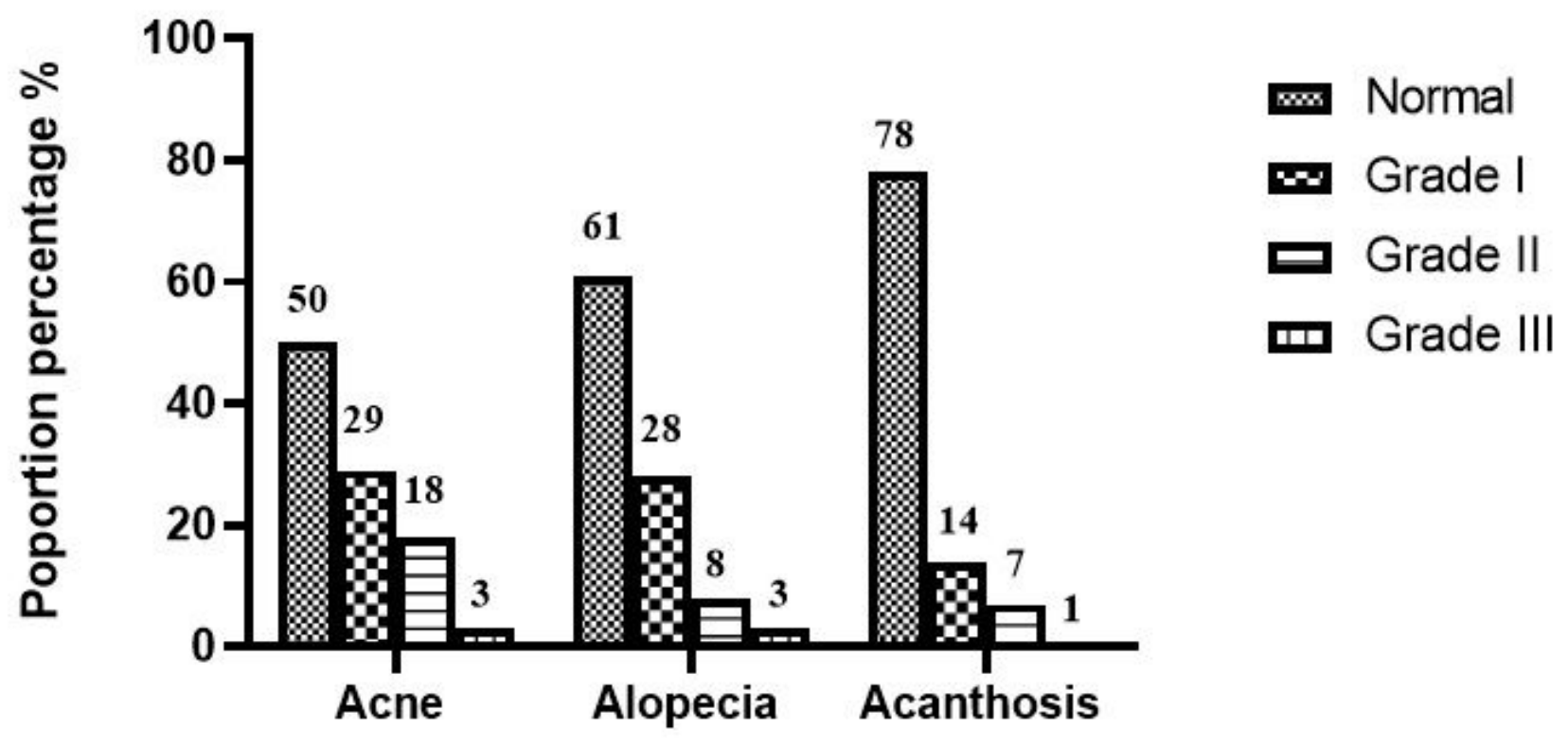

Figure 1

Distribution of acne vulgaris, androgenic alopecia and acanthosis nigricans in women with PCOS 

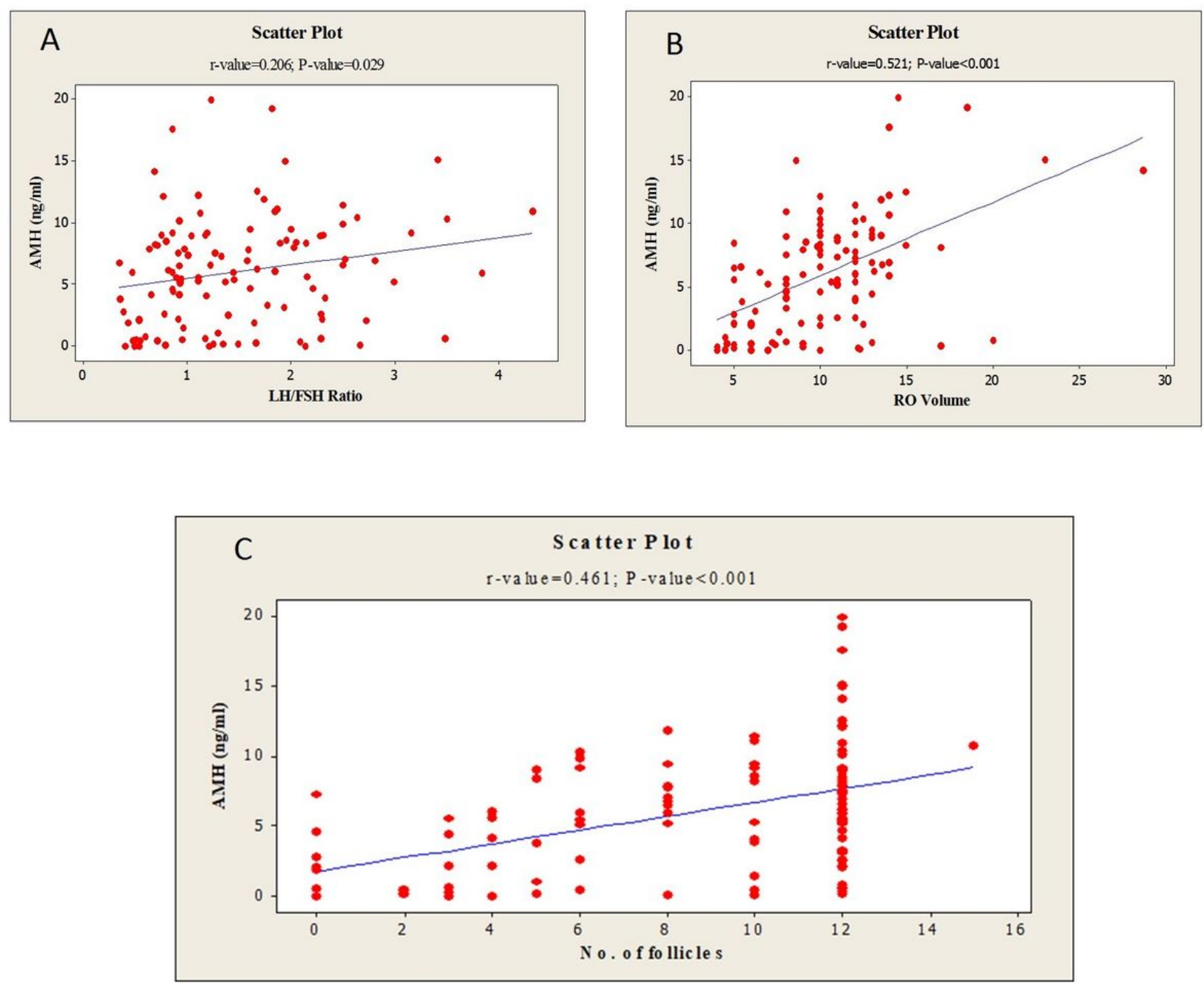

\section{Figure 2}

Scatter plots showing correlation of serum $\mathrm{AMH}$ levels with LH/FSH ratio (A), ovarian volume(B) and follicle number(C) in women with PCOS. 


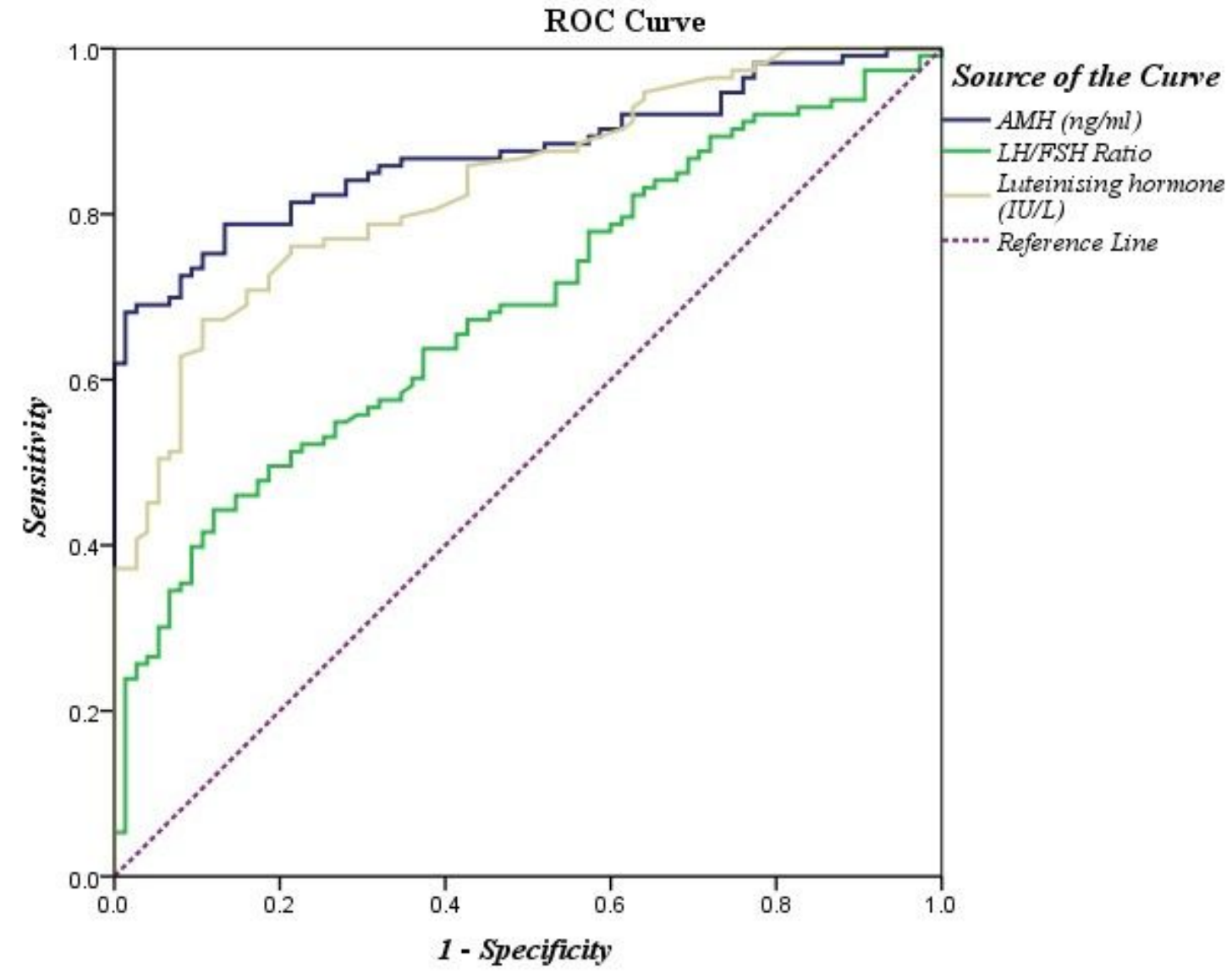

Figure 3

Receiver operating characteristic (ROC) curve of $\mathrm{AMH}$ for predicting PCOS among women 